\title{
TRABALHO, EDUCAÇÃO E SAÚDE: O PONTO DE VISTA ENIGMÁTICO DA ATIVIDADE
}

\author{
WORK, EDUCATION AND HEALTH: \\ THE ENIGMATIC POINT-OF-VIEW OF ACTIVITY
}

\author{
Jussara Brito 1 \\ Milton Athayde 2
}

Resumo Propomo-nos, aqui, a refletir sobre trabalho-educação-saúde a partir de um programa que conjugou pesquisas e formação de trabalhadores de escolas públicas sobre as relações saúde-trabalho, cuja perspectiva epistemológica estava centrada na atividade de trabalho e na confrontação entre conhecimento científico e saberes e indagações advindas da experiência dos trabalhadores. Constituindo uma 'comunidade ampliada de pesquisa', que associa pesquisadores e trabalhadores, pretendemos contribuir para a compreensão das dinâmicas e condições que podem gerar sofrimento e conduzir ao adoecimento ou, em contrapartida, possibilitar a emergência de estratégias de afirmação da vida e da saúde, considerando os conflitos de valores presentes nas situações de trabalho do serviço público. Buscamos, sobretudo, contribuir para a identificação das questões efetivas a serem enfrentadas com vistas às mudanças que os trabalhadores considerem prioritárias. Ao descrever esse programa e apresentar alguns elementos relativos à sua evolução e a seus resultados, sinalizamos a necessidade de construção de métodos de pesquisa segundo a premissa de que os trabalhadores detêm uma experiência e um tipo de saber imprescindíveis para compreender essa relação sempre enigmática entre saúde e trabalho na perspectiva de promoção da saúde e da afirmação da vida.

Palavras-chave trabalho em escola; saúde do trabalhador; gênero; formação; comunidade ampliada de pesquisa.
Abstract In this article we intend to make a discussion about work-education-health, taking as reference one Program that conjugated researches on the relation health-work and formation of male and female workers of public schools, whose epistemological perspective was centered in the work activity and in the confrontation among scientific knowledge and the knowledge generated on the workers' experience. Constituting an 'amplified community of research', that associates researchers and workers in the same process, we intended to contribute for the understanding of the dynamics and conditions that can generate suffering and sickness or can facilitate the creation of strategies of life's and health's statement, considering the values conflicts that are present in the public service's work. Above all things, we tried to contribute for the identification of the effective problems to be faced, aiming to make the changes that the workers consider as priorities. After presenting this program and some of it's results, we signalled the necessity of the construction of research methods compatibles to the premise that the workers are detainers of an experience and an indispensable type of knowledge to the comprehension of the enigmatic relation between health and work, in the approach of promotion of health and statement of life.

Key words work in school; worker's health; gender; formation; amplified community of research. 


\section{Introdução}

Este artigo é o resultado de uma experimentação que conjugou pesquisa e formação de trabalhadores e trabalhadoras de escolas públicas sobre as relações entre saúde e trabalho. Considerando a especificidade do objeto de investigação científica, procuramos reduzir os efeitos negativos de "uma postura de exterritorialidade"3 (Schwartz, 2000a, p. 71), no que concerne à relação do pesquisador com a análise de seu objeto, uma forma de análise das questões do mundo do trabalho baseada exclusivamente em quadros analíticos construídos externamente, em princípio, distantes da complexidade permanentemente engendrada onde a história singular acontece.

Esta perspectiva epistemológica e metodológica apóia-se, primeiramente, na compreensão que temos do que é viver e trabalhar e, em segundo lugar, na avaliação de que os limites do conhecimento científico sobre saúde e trabalho só podem ser superados se confrontados e estimulados pelos desafios e pelas indagações advindos da experiência - portada na primeira pessoa - daqueles que vivem as relações que investigamos.

Nosso ponto de partida é o vivente humano em sua vitalidade, em sua atividade. Trata-se de um ser vivo, conforme Canguilhem (1992), que vive seu meio em uma atividade de oposição à inércia e à indiferença, um ser mais que normal, 'normativo', criativo, capaz de produzir novas normas em seu meio (Canguilhem, 1990). Daí o conceito de 'atividade de trabalho', utilizado por disciplinas diversas, sempre remetendo à demanda por renormatização e inventividade e ao caráter não totalmente padronizável da vida e do trabalho. Em Marx (1948, p.181), encontramos “a atividade pessoal do homem ou trabalho propriamente dito" (incorporada como força de trabalho pelo capital) como um dos três elementos do processo de trabalho. Dando continuidade à análise deste processo e das relações que se estabelecem entre seus elementos, evidenciou-se que o trabalho não pode ser reduzido à prescrição.

$\mathrm{Na}$ verdade, esta foi uma crença, uma das ficções criadas sob o regime capitalista de extração de mais-valia. Neste caso, uma derivação dogmática da perspectiva de Taylor, a chamada "organização científica do trabalho" (ou taylorismo). A vida - e o trabalho como manifestação da vida - escapa a qualquer tentativa de antecipação rígida: “a vida, e mais exatamente a atividade [...] não se prestam a esta lisibilidade dócil" (Schwartz, 2000a, p. 81). E os trabalhadores, mesmo taylorizados, escapam a qualquer tentativa de objetivação (ou "alienação"); afinal, "todo homem quer ser sujeito de suas próprias normas" (Canguilhem, [1947] 2001, p. 120). O que a pesquisa descobre é que a atividade nunca é inteiramente heterodeterminada.

$\mathrm{O}$ conceito de atividade é, portanto, decisivo. Para além de qualquer fetichismo operatório ${ }^{4}$, o conceito ampliado de atividade recusa a neutralização das dimensões subjetivas da ação e permite compreender o trabalho co- 
mo um lugar permanente de microescolhas - de debate de normas e valores (Schwartz, 2000a). No trabalho, o sujeito é colocado diante de diferentes racionalidades (racionalidade como norma imposta e racionalidade do próprio coletivo de trabalhadores) e valores (econômico, social, político, de solidariedade, saúde etc.).

Mesmo na atividade percebida como o mais simples ato de execução, os trabalhadores são desafiados e constrangidos a fazer escolhas, decidir caminhos, mesmo que no infinitesimal; enfim, desafiados e constrangidos a renormatizar, em meio às prescrições e aos seus próprios referenciais de vida. "Trabalhar é, queira-se ou não, engajar uma parte de si-mesmo em uma atividade dominada pelas forças estrangeiras do capital" (Faïta e Schwartz, 1985, p. 11). “De fato, para não se cair na pura abstração (o universal), torna-se sempre necessário restituir as formas concretas, sociais e históricas da atividade que dão vida e realidade às suas características gerais" (Duc, 2002, p. 49).

Esse caráter singular das situações de trabalho é apreendido pela Ergonomia da Atividade através do conceito de 'variabilidade', que registra o caráter não previsível das situações de trabalho, incluindo o que é gerado pelas novas tecnologias e formas de organização do trabalho, pelas exigências de flexibilidade, pela influência do tempo (duração e turno do trabalho; envelhecimento) no desempenho e na saúde dos indivíduos e, ainda, pelas características individuais e populacionais (Montmollin, 1997).

Com os conceitos de 'trabalho prescrito' e 'trabalho real', tarefa (o que se deve fazer) e atividade (o que se faz), esta Ergonomia (Leplat; Hoc, 1983) introduz uma distinção clara entre as tarefas previamente planejadas pela direção (impostas ao trabalhador) e a atividade efetivamente posta em funcionamento para dar conta da produção, das limitações da prescrição e da variabilidade sempre presente e nem sempre previsível.

De fato, a instabilidade é uma característica das situações de vida e trabalho, pois, nas palavras de Canguilhem (1990), o meio é sempre infiel, sendo a saúde uma margem de tolerância às infidelidades do meio, a capacidade de criar novas normas (trata-se, então, de uma dupla infidelidade). É nesse sentido que Canguilhem fala das reações dos trabalhadores em relação à organização taylorista do trabalho:

“As reações operárias à extensão progressiva da racionalização taylorista, revelando a resistência do trabalhador 'às medidas que lhe são impostas do exterior' devem, portanto, ser compreendidas tanto como reações de defesa biológica quanto como reações de defesa social e, nos dois casos, como reações de saúde" (Canguilhem, [1947] 2001, p. 116).

Mas é preciso ir adiante em relação a esta conquista da Ergonomia da Atividade, evitando mutilá-la, ampliando o conceito de atividade de traba- 
lho, distinguindo realidade e real do trabalho, ou atividade realizada e atividade real. Conforme Clot et al. (2001, p. 18), "para nós, o real da atividade é igualmente aquilo que não se faz, o que se procura fazer sem lograr êxito o drama dos fracassos - , o que se poderia ter feito ou desejado fazer, o que se pensa poder fazer em outros lugares".

Ou seja, a atividade não se resume ao que é feito, o que a Ergonomia da Atividade denomina trabalho real. Para os autores, que se baseiam nas contribuições da escola russa de Psicologia fundada por Vigotski - para quem “o homem é, a cada minuto, pleno de possibilidades não realizadas" (Vigotski, 1994, p. 41) —, a atividade de trabalho envolve também o que não se faz, o que se busca fazer sem conseguir, o que poderia ter sido feito, o que há para refazer e até o que se faz sem querer.

Paradoxalmente, o que se faz para não fazer o que se está por fazer, pois muitas vezes fazer é, por outro lado, refazer ou desfazer. As atividades contrariadas ou impedidas, mesmo as contra-atividades - toda esta riqueza e complexidade - precisam ser acolhidas na análise da atividade, esclarecendo seus conflitos. A existência dos sujeitos é traçada nestes conflitos. Como nos diz Clot, “a atividade é uma prova subjetiva em que a pessoa se mede, a si e aos outros para ter uma chance de chegar a realizar o que está por fazer. O realizado não tem mais o monopólio do real. O possível e o impossível fazem parte do real" (Clot et al., 2001, p. 8).

Entendendo o trabalhar como um modo de se inscrever na história da humanidade, de inscrição simbólica na vida social, podemos acompanhar esta ampliação do conceito de atividade. Operando fora de uma perspectiva psicogenética, não se trata da atividade em si, o objeto de conhecimento é o desenvolvimento das atividades do sujeito e seus impedimentos e menos a atividade como tal (Clot, 1999).

Com base nessas concepções de trabalho e saúde, desenvolvemos um programa de pesquisas contendo um programa de formação de trabalhadores/as de escola em saúde-trabalho, experimentação a partir da qual procuraremos desenvolver este artigo, atentos para a possibilidade de que alguns de nossos aprendizados e descobertas nesse processo sejam úteis para outras experimentações, com outros grupos de profissionais, especialmente os do setor saúde.

Primeiro, vamos apresentar e analisar o quadro de saúde-doença dos trabalhadores/as de escola, tendo como referência os estudos que realizamos e os resultados de outras pesquisas. Em seguida, vamos nos dedicar aos aspectos epistemológicos e metodológicos da experimentação de pesquisa-formação junto aos referidos trabalhadores/as, debatendo alguns dos resultados alcançados.

Em nossa análise, buscamos incluir não apenas professores/as, mas também merendeiras e serventes. O olhar sobre esse conjunto de profissionais 
justifica-se. Primeiro, porque partiu de uma solicitação do movimento dos trabalhadores/as de escola no estado do Rio de Janeiro, através de seu sindicato (SEPE-RJ); segundo, porque, em nosso entendimento, é o conjunto desses segmentos, em relação, que fazem funcionar a escola, apesar de todas as dificuldades.

\section{A problemática da saúde dos trabalhadores/as de escola}

Os estudos que realizamos inicialmente - de caráter qualitativo, realizando entrevistas dialógicas, observações e análises das atividades - esboçaram um cenário em que a saúde dessa população de trabalhadores/as mostrou-se, no geral, muito comprometida (Brito, Athayde \& Neves, 1998; Brito et al., 2001), em desacordo com a representação que se costuma ter da escola, à diferença de ambientes industriais.

Entre as merendeiras e serventes entrevistadas foram constantes as referências a determinados sintomas ou patologias: problemas de coluna, varizes, perda de força, dormência e edema nas mãos, rigidez matinal, dor no peito, problemas dermatológicos, respiratórios, pulmonares e intestinais, irritabilidade, hipertensão, "estresse".

Quando agrupamos essas queixas em sinais e sintomas relacionados a LER/DORT (respectivamente, "lesão por esforço repetitivo" e "distúrbio osteomuscular relacionado ao trabalho"), problemas do aparelho cardiovascular, alterações do comportamento, problemas ginecológicos e outros (problemas renais, anemia intensa, cansaço, dor no peito, problemas de visão, falta de ar, verminose), concluímos que foram especialmente significativas as queixas referentes aos três primeiros grupos (Brito et al., 1998).

Utilizando outro dispositivo, que denominamos Oficinas de Saúde (bairro de Madureira/RJ), com um grupo de merendeiras e serventes, outro problema foi revelado: o uso de medicamentos para dormir, sem acompanhamento médico, certamente associado ao "estresse" de que se queixaram (Souza, 2000).

Verificamos que, na realização da atividade docente, surgem determinados tipos de problemas de saúde, expressos como mal-estar geral, falta de ar, pressão baixa, tonturas, cansaço, labirintite, esgotamento físico e mental, problemas nas cordas vocais, problemas respiratórios, alergias, rinite, perturbações do sono (insônia e sono que não é reparador), perturbações de caráter digestivo, formas de alimentação inadequadas (podendo implicar a médio e a longo prazo em deficiências nutritivas), "estresse", aumento nos níveis de ansiedade, frustração, angústia, depressão e irritabilidade (Gomes, 2002). Tratase de um conjunto de problemas que se potencializam ao final do ano letivo.

Conforme uma perspectiva de cruzamento de métodos de investigação, analisamos, através do programa Epi-Info (versão 6.0), os dados oficiais so- 
bre "readaptação profissional"5 coletados junto à Superintendência de Saúde e Qualidade de Vida do Governo do Estado do Rio de Janeiro, referentes a um período de cinco anos (1993-1997), considerando a readaptação como um indicador do quadro de saúde-doença no trabalho. Verificamos que a incidência de casos de "readaptação" ao longo desses anos foi crescente para quase todos os segmentos profissionais.

Quando analisamos os casos novos de readaptação no período, segundo a especialidade clínica, observamos que as mais relevantes para merendeiras e serventes, respectivamente, foram cardiologia $(29,6 \%$ e $34,7 \%)$, ortopedia $(19,7 \%$ e $20,2 \%)$, reumatologia $(17,9 \%$ e $15 \%)$ e clínica médica $(10,9 \%$ e $9,4 \%)$. Em relação às professoras, destacaram-se a psiquiatria $(26,8 \%)$ e a otorrinolaringologia $(24,6 \%)$, seguidas da cardiologia (12\%) e ortopedia (8,5\%). Entretanto, de 1993 a 1997, a freqüência de readaptações concedidas pela cardiologia diminuiu para merendeiras e serventes, bem como para professores.

Diferentemente, nesse período houve um aumento importante de casos novos de readaptação de merendeiras e serventes ligados à ortopedia, reumatologia, clínica geral e dermatologia. O crescimento da freqüência de readaptação entre professoras nesses anos concentrou-se na otorrinolaringologia, psiquiatria e ortopedia. É importante sinalizar que na ortopedia e na reumatologia são atendidos trabalhadores com problemas osteoarticulares, cuja relação com a hiper-solicitação de músculos e articulações no processo de trabalho são evidentes.

Merece também atenção o fato de que, para os professores/as, ampliaram-se as readaptações por problemas vocais, evidenciando modificações nas condições e na organização do trabalho, que tornaram o trabalho docente mais nocivo ao longo dos cinco anos pesquisados. Analisando conjuntamente as readaptações por idade e tempo de serviço, verificamos que as pessoas com mais idade tiveram a primeira readaptação concedida com mais tempo de serviço. Já as mais novas com menos tempo de serviço. Com certeza, esta realidade configura um quadro perverso para cada trabalhador atingido e para a sociedade.

Através de pesquisa bibliográfica, constatamos que a quase totalidade dos estudos que tratam do trabalho em escolas foca exclusivamente o trabalho docente, com ênfase na questão da saúde mental. Na Argentina, Martinez et al. (1997) têm procurado desenvolver a categoria de análise "mal-estar docente"6, tendo como referência José Manoel Esteve (1994).

Em suas pesquisas, eles têm buscado construir indicadores de sofrimento e de riscos nas escolas. Com a Pesquisa Nacional da Confederação de Trabalhadores de Educação da República Argentina, desenvolvida com esse marco teórico e aplicada a 336 escolas e 3.455 professore/as, esses pesquisadores chegaram a um conjunto de conclusões, entre as quais destacamos: 
tempo de trabalho excessivo (38,6\% disseram trabalhar entre 20 e 30 horas semanais na escola; $41,2 \%$ afirmaram que o tempo dedicado ao trabalho docente fora da escola é de mais de 16 horas; 35,8\% gastam 35 horas ou mais no trabalho doméstico semanal); patologias diagnosticadas em mais de $20 \%$ da população estudada (resfriados, disfonia, vertigem, varizes, alergia, miopia, estresse, gastrite); transtornos psicossomáticos relatados (maior freqüência para nervoso permanente, 49\%; dificuldade de concentração, 38,9\%; angústia, 37,9\%; insônia, 27\%; e perda de memória, 25\%).

No Equador (Betancourt e Palacios, 1999) realizou-se também uma pesquisa, de caráter quantitativo, por meio de questionários aplicados (por professores previamente capacitados) a uma amostra de 1.915 trabalhadores (68,3\% mulheres), em 238 escolas. Conjugaram a verificação dos dados obtidos com observações das condições de trabalho e do entorno das escolas.

Nos questionários dirigidos às escolas, consideraram-se variáveis diversas relacionadas às características dos edifícios, à infra-estrutura, às condições ambientais e ao número de docentes. No questionário individual, constam questões sobre condições de trabalho (salário, organização e cargas de trabalho, formação docente etc.) e de vida, morbidade sentida, licenças por enfermidade, alimentação e consumo.

Vários foram os problemas levantados nessa investigação, alguns provavelmente universais e outros específicos. O ruído é um exemplo de problema possivelmente universal, que teve como fontes identificadas a via pública, a voz humana e o número excessivo de alunos por área. Em relação aos sintomas relatados nas entrevistas individuais, sobressaíram-se aqueles relacionados à saúde mental: enfraquecimento (no sentido de estar abatido, "derrubado"), nervosismo, angústia, irritabilidade, choro fácil, dificuldade de concentração, insônia e desinteresse sexual.

A investigação de Codo et al. (1999)7, específica sobre saúde mental de professores/as de todo o país, indicou que $26 \%$ da amostra apresentavam exaustão emocional, sendo a desvalorização profissional, a baixa auto-estima e a ausência de resultados percebidos no trabalho os principais fatores para a configuração deste quadro. Já Araújo e colaboradores (1998) 8 demonstraram que entre os professores/as da rede particular as queixas mais relevantes foram as relacionadas ao uso contínuo da voz (dor na garganta, rouquidão), à postura corporal adotada no exercício das atividades (dor nas costas e pernas) e às repercussões dessas atividades no funcionamento psico-emocional (cansaço mental, nervosismo).

A essas queixas foram associadas às seguintes características das condições de trabalho: salas inadequadas, trabalho repetitivo, exposição à poeira, ambiente intranqüilo e estressante, ritmo acelerado de trabalho, desempenho das atividades sem materiais e equipamentos adequados e posição de trabalho incômoda. 
Em pesquisas com professoras de ensino fundamental da rede municipal de João Pessoa, Neves (1999) cita, no que se refere ao sofrimento (no sentido atribuído por Dejours, 1993), a recorrência de queixas relativas ao cotidiano escolar que levam as professoras a um mal-estar.

Esse sofrimento estaria ligado à formação deficiente, à dificuldade para operar regras de ofício (como a do controle de turma), à inexistência de espaços de intercâmbio profissional e de planejamento das atividades docentes, às relações hierárquicas, à falta de pessoal e de material nas escolas, à insuficiência de pausas e de momentos de lazer e descanso, à tripla jornada de trabalho, à contaminação das relações familiares pela invasão das atividades escolares no espaço domiciliar e, sobretudo, à desqualificação, aos baixos salários e ao não reconhecimento social de seu trabalho.

Além disso, essa pesquisa contempla também uma abordagem dos "movimentos de resistência e luta contra a insatisfação, a indignidade e a desqualificação decorrentes da organização do trabalho docente, que terminam por contribuir, em certa medida, para reorganizá-lo" (Neves, 1999, p. 246).

Assim como Neves, Carpentier-Roy (1992) e Barros (1997) fornecem importantes pistas para a indicação de ações preventivas estratégicas. Carpentier-Roy (1992) procurou identificar os elementos que contribuem com os professores/as em seu esforço para manter a saúde, para evitar "escorregar" em direção ao burnout. Barros (1997), com sua reflexão sobre a experiência desenvolvida em Vitória, gestão 1989-1992 da Secretaria Municipal de Educação, mostrou que, nessa época, a rede municipal de educação de Vitória adquiriu 'mais dignidade': algumas parcerias se efetivaram e muitos encontros foram possíveis, sendo viabilizadas outras práticas educacionais e, conforme os/as professores/as, "os gritos viscerais não ficavam entalados nas gargantas".

Vemos, a partir desse acervo científico, que ao trabalho na escola estão associados muitos agravos. Perguntamo-nos: como mudar esta situação? Entendemos que é preciso ter como ponto de partida não apenas o quadro de nocividade presente, mas a compreensão das múltiplas articulações entre saúde e trabalho na escola, a apreensão das variabilidades dos processos de trabalho e as formas de antecipação e regulação encontradas. Não só o registro das dificuldades concretas com as quais os trabalhadores se deparam, mas as estratégias já encontradas no cotidiano de suas atividades para garantir um mínimo de qualidade para o trabalho na escola, para sua vida e para sua saúde.

Um projeto nada simples, pois temos percebido uma grande heterogeneidade entre as escolas das redes públicas, dado um quadro geral de precarização. O estilo de resistência e de afirmação da vida revela uma micropolítica a ser mais bem compreendida.

As escolas, como os serviços de saúde, são locais de trabalho onde há normas comuns ao conjunto da rede a que estão vinculadas. No entanto, 
existem normas específicas, nem sempre formalizadas de forma escrita, em cada escola, devido à sua localização geográfica e às características da clientela, entre outros fatores. Como outras atividades do serviço público, tratase de trabalho fortemente marcado pela singularidade, envolvendo conflitos de valores: tanto os adjacentes ao trabalho educativo, quanto os defendidos pelos grupos que desenvolvem esse trabalho em cada escola.

Em cada ação, os trabalhadores de escola são confrontados com esses valores, o que é a essência de suas "dramáticas do uso de si no trabalho" (Schwartz, 1992): a professora que decide elaborar as apostilas para uso dos alunos, mesmo sem ser remunerada por isso; a merendeira que chega mais cedo na escola para que a refeição fique pronta na hora esperada.

Pensamos ser fundamental desenvolver estudos e ações considerando esses trabalhadores como sujeitos que vivem essas dramáticas do trabalho. Acreditamos que o desafio é duplo: compreender e transformar o trabalho em cada escola e, simultaneamente, criar dispositivos que possibilitem uma intervenção mais ampla, isto é, em um conjunto de escolas da rede. O Programa de Formação em Saúde, Gênero e Trabalho nas Escolas Públicas foi concebido nesse contexto e meio a essas preocupações.

\section{Aspectos teórico-metodológicos do Programa de Formação em Saúde, Gênero e Trabalho nas Escolas Públicas}

Com a perspectiva de compreender-transformar o trabalho nas escolas, desenvolvemos um programa de pesquisas incluindo um programa de formação, com base na construção de uma rede de encontro de saberes, que envolve os saberes práticos, de quem vive a experiência, e os saberes científicos, oriundos das disciplinas epistêmicas que tratam desta temática.

Com esse sistema de co-análise — associando pesquisadores e trabalhadores no mesmo processo, ajudando-os a "trabalhar" a própria experiência, colaborando para que ela possa exprimir suas potencialidades - pretendemos contribuir para a compreensão das dramáticas do trabalho na escola, dos processos, das dinâmicas e condições que podem gerar sofrimento e conduzir ao adoecimento ou possibilitar a emergência de estratégias de afirmação da vida e da saúde. Tentamos, sobretudo, contribuir para a identificação das questões efetivas a enfrentar, com vistas às mudanças que os coletivos de discussão entendam como prioritárias.

Buscamos inspiração em propostas já formuladas e experimentadas com sucesso. O patrimônio oferecido pelo Movimento Operário Italiano de Luta pela Saúde continua sendo uma das fontes destacadas. Por exemplo, o dispositivo que Ivar Oddone e seus colaboradores $(1981$; 1986) denominaram 'comunidade científica ampliada', que permite colocar em relação de coo- 
peração produtiva os especialistas em saúde-trabalho, os sindicatos e os próprios trabalhadores, tendo como eixo a experiência prática sobre a atividade realizada, algo sempre em movimento e distinto do que é suposto por todos que não participam diretamente desse processo ${ }^{9}$, mesmo os especialistas em saúde-trabalho.

Vicenti (1999, p. 35) relata o que significou essa experiência sob o ponto de vista da produção de conhecimento:

“O conjunto de atores - médicos, sociólogos, psicólogos, estudantes, trabalhadores e sindicalistas (...) - deu início às comunidades científicas ampliadas, que se desenvolveram sobre todo território nacional e que, através da confrontação entre os saberes formais dos pesquisadores e os saberes informais dos trabalhadores, elaboraram uma nova concepção de pesquisa. Em torno do tema das mudanças das condições de vida e de trabalho, essas comunidades desenvolveram uma forma original de pesquisa-ação, que Ivar Oddone chamou de 'pesquisa não ritual', porque ela mexeria com os métodos da pesquisa tradicional. Com efeito, nessas experimentações, todos os atores se tornariam co-autores da pesquisa enquanto portadores de seus saberes específicos e, em particular, os trabalhadores enquanto portadores de saberes informais (experiência)" (Vicenti, 1999, p. 35).

Como uma forma de luta pela saúde (como instrumento de afirmar a vida) e uma forma de produção de conhecimento sobre o ambiente de trabalho, esse movimento estava articulado a quatro conceitos: grupo homogêneo, observação "espontânea", validação consensual e não delegação. Trata-se de um patrimônio que se tornou referência para a formulação do campo da Saúde do Trabalhador, tendo em vista a divulgação da experiência italiana, através do intercâmbio e visitas de técnicos e profissionais de saúde à Itália (Dias, 1994). Esses conceitos (Oddone et al., 1986) nos remetem, respectivamente:

a) A um grupo que vive submetido à mesma nocividade e que acumulou um saber epidemiológico leigo sobre o ambiente no que diz respeito às relações entre o ambiente e os sofrimentos e adoecimentos que o acometem;

b) Aos primeiros dados sobre a nocividade, fornecidos pela observação autônoma dos trabalhadores (em relação a intervenções externas ao grupo), ainda pouco elaborada, primeiro momento de conhecimento leigo, primeira hipótese, mas extremamente eficaz;

c) Ao conjunto de julgamentos subjetivos e qualitativos dos trabalhadores quanto às condições de trabalho, oferecendo a credibilidade necessária para que as análises e soluções possam tornar-se instrumento na luta pela transformação. Neste mesmo movimento, o grupo toma consciência do alcance cultural de sua experiência e se reconhece como grupo homogêneo;

d) Ao objetivo metodológico fundamental contido na tendência a não delegar aos especialistas o julgamento sobre a nocividade das condições de 
trabalho do grupo e a fixação dos limites de nocividade, o que colocava em questão a interpretação dos resultados das análises científicas, que seriam aceitas somente após validação por parte do grupo homogêneo.

Assim, coerentes com a tradição conquistada no campo da Saúde do Trabalhador, buscamos um modo de produção de conhecimento, constituindo e desenvolvendo um espaço de diálogo crítico entre nós, pesquisadores profissionais, e os trabalhadores envolvidos, em que fosse possível compartilhar informações e percepções sobre a atividade de trabalho na escola, bem como sobre as questões de saúde relacionadas. À luz da contemporaneidade — e do duplo desafio que mencionamos — , pensamos que esse espaço deveria assumir a forma de uma rede, que preferimos denominar provisoriamente de 'comunidade ampliada de pesquisa', dado que essa rede pretende a mobilização de saberes não apenas científicos.

Para melhor fundamentar nosso projeto, buscamos outros referenciais que aprofundassem o debate acerca da produção de conhecimento sobre o trabalho e suas relações, destacando a importância dos 'saberes informais'. Também valorizando a riqueza das experimentações realizadas na Itália e as proposições de Oddone (op. cit.), Schwartz (2000b) desenvolve uma concepção extremamente fértil. Ele critica a expressão 'comunidade científica ampliada', entendendo que ela pode ocultar as competências de cada um dos parceiros, bem como deixar de evidenciar a dificuldade existente em um tipo de proposta que tem como base o diálogo e a parceria entre pesquisadores e os vários protagonistas do mundo do trabalho.

Com essas considerações, Schwartz desenvolve um outro instrumento conceitual-metodológico denominado "dispositivo em três pólos". Trata-se de um dispositivo que lança um regime de produção de conhecimento com base na articulação entre os materiais gerados pelas diferentes disciplinas científicas (pólo dos conceitos), os saberes e valores gerados pelas experiências dos trabalhadores nas atividades (pólo das "forças de convocação e de reconvocação") e, por fim, o pólo das exigências éticas e epistemológicas (também metodológicas), indispensáveis para fazer a gestão do encontro dos dois primeiros pólos, tornando-os fecundos.

Schwartz, com esse terceiro pólo, enfatiza a ética necessária à construção das relações de parceria, apoiada em determinada filosofia da humanidade em que se busca aprender com o outro o que ele faz e como o faz. Esse dispositivo dinamiza a relação entre o conhecimento científico e a experiência, tendo como princípio as "mútuas convocações", combinando desconforto intelectual e humildade epistemológica, pois tanto os trabalhadores podem enriquecer seus saberes específicos em contato com as diversas disciplinas, como essas mesmas disciplinas só podem se desenvolver a partir das "forças de convocação", ou seja, das questões trazidas pelos mundos do trabalho, questões muitas vezes desconhecidas e sem respostas por parte das ciências. 
Para Schwartz (2000a), a ambição de generalização, própria das ciências, se não regulada adequadamente, pode acabar neutralizando os aspectos singulares da experiência, uma fonte potencial de compreensão das situações de trabalho e que permite a apreciação dos limites dos conceitos.

O Programa de Pesquisas e o Programa de Formação em Saúde, Gênero e Trabalho em Escolas se desenvolveram de maneira interdependente e foram formulados com base nessas concepções teórico-metodológicas, incorporando também uma perspectiva de gênero, sobre a qual cabe um esclarecimento. O trabalho na escola é operado fundamentalmente por mulheres e esta construção sócio-histórica evidentemente dá visibilidade para uma questão em geral ocultada. O paradigma da transversalidade das relações de gênero (em relação às outras relações sociais) deixa visível a necessidade de construirmos metodologias não dicotômicas, evitando centrar as análises seja no espaço da produção, seja no espaço da reprodução/família, uma vez que “a relação entre os sexos não se esgota na relação conjugal, mas é ativa no lugar de trabalho; a relação de classes não se esgota no lugar de trabalho, mas é ativa na relação com o corpo ou com as crianças" (Kergoat, 1996).

As relações sociais e a divisão sexual do trabalho estão no centro das análises dessa abordagem. A perspectiva de transversalidade demonstra que as relações de gênero organizam e estruturam o conjunto das relações sociais (Scavone, 1999). A noção de valor do trabalho está vinculada às relações de gênero e engendra precariedade e precarização do trabalho das mulheres. Os estudos sobre trabalho doméstico tiveram um papel decisivo no alargamento do conceito de trabalho, instrumentando para a compreensão das novas estratégias laborais engendradas no mundo contemporâneo, que para tantos significaria o fim do trabalho.

Para Hirata (2000), a divisão sexual do trabalho tem muitas conseqüências sobre as modalidades de participação social e no trabalho das mulheres. Entre elas, o valor simbólico do trabalho e a questão dos estereótipos de virilidade e feminilidade explorados no âmbito do trabalho. Sobre o valor simbólico do trabalho, destaca que a entrada das mulheres no mercado de trabalho assalariado é marcada, desde a industrialização, pela desvalorização do posto de trabalho que passam a ocupar, inclusive implicando redução dos salários.

Lança, como hipótese explicativa, a gratuidade do trabalho doméstico: se as mulheres realizam trabalhos gratuitamente, quando são assalariadas, poderiam também receber um salário menor. Como se referem ChabaudRychter, Fougeyrollas-Schwebel e Sonthonnax (1985), a “disponibilidade permanente" das mulheres na esfera doméstica é uma relação social que supõe gratuidade dos serviços prestados.

A divisão sexual do trabalho interfere na produção social do processo saúde/doença: 
"Para os trabalhos masculinos, a exaltação da virilidade e dos estereótipos que lhes são associados (força, coragem etc.) permitem balizar uma parte dos riscos e opera, em certas profissões, uma verdadeira seleção entre os trabalhadores. Para os trabalhos femininos, o recurso a determinados estereótipos permite toda vez negar as qualificações reais (e, para além, permite justificar as desigualdades salariais e a fraca participação nas decisões) e os riscos para a saúde das tarefas descritas como 'naturalmente femininas'" (Vogel, 2000, p. 13).

O fato de as mulheres serem levadas a uma dupla ou tripla jornada de trabalho e a operar em determinadas atividades no âmbito da produção que se repetem no cotidiano reprodutivo, além do não reconhecimento de seu fazer, pode fragilizar a 'economia psicossomática' e levar as mulheres ao adoecimento e a transtornos psíquicos graves.

\section{Caracterização das fases do Programa}

O Programa de Formação em Saúde, Gênero e Trabalho em Escolas foi construído no interior de um programa de pesquisas, constituindo-se em sistema que procurou dar conta de um pedido de ajuda formulado pelo movimento dos trabalhadores de escola do Rio de Janeiro, através de seu sindicato (SEPE-RJ).

Simultaneamente instrumento de pesquisa e de formação dos trabalhadores na defesa da vida e da saúde no trabalho, este sistema possibilitou a preparação de todos os participantes para uma escuta mais refinada e uma discussão sistemática sobre tais questões nos locais de trabalho. Ele pode ser considerado um método indireto de análise das situações de trabalho, na linhagem de Vigotski (1994), pois procura romper com a abordagem definida externamente, bem como favorecer a construção de discursos resultantes da situação de trabalho, constituindo-se um outro regime de produção de conhecimento.

Concebido para ser realizado em ciclos, visando à multiplicação desta formação, o sistema prevê a participação dos trabalhadores. Desta forma, os participantes do primeiro ciclo de formaçãol0 ("multiplicadores") assumem gradativamente, junto com a equipe de pesquisadores, a responsabilidade pela formação dos trabalhadores do segundo ciclo de formação ("multiplicadores de base") e assim por diante.

Em cada ciclo foi se multiplicando o número de envolvidos no Programa, uma vez que cada participante, nesse processo, foi construindo uma 'comunidade ampliada de pesquisa' em sua escola ou região de trabalho e/ou atuação sindical, constituindo-se uma rede de estudo e intervenção sobre saúde-trabalho nas escolas públicas. Devido ao caráter da proposta, que 
envolve estudos de campo e um processo continuado de multiplicação, preferimos lidar com um pequeno número de participantes em cada ciclo de formação, viabilizando os contatos "face a face" e o desenvolvimento de uma dinâmica sócio-afetiva do que se pode denominar fazer grupo ou grupo-dispositivo (Benevides Barros, 1994). Assim, no primeiro ciclo de desenvolvimento desse Programa no Rio de Janeiro, participaram 14 trabalhadores.

Nosso plano inicial era fazer com que cada participante do primeiro ciclo fosse capaz de mobilizar dez colegas para participar desse Programa, de forma que teríamos 150 pessoas envolvidas e preparadas para construir o esboço de um observatório das relações entre saúde, gênero e trabalho em suas escolas, com vistas a criar um observatório geral. Esse observatório, mesmo tendo formato singular em cada local de trabalho, daria rapidamente visibilidade às descobertas realizadas desde os ciclos de formação e seria uma fonte de dados para monitoramentos e análises continuadas, tendo em vista a promoção da saúde, particularmente através do que se costuma denominar "sistema de vigilância" em saúde.

A base inicial para a construção desse observatório estaria nos relatórios produzidos pelos trabalhadores em seus estudos de campo, pois em cada ciclo desenvolveram-se as seguintes fases: um curso sobre o tema Saúde, Gênero e Trabalho nas Escolas Públicas; retorno dos participantes às suas escolas para exercícios de estudo de campo11; encontros, após cada exercício, para compartilhar as descobertas feitas durante os estudos de campo com os colegas do grupo e pesquisadores - a 'comunidade ampliada de pesquisa'.

\section{Fase 1: 0 curso sobre a temática}

\section{"Saúde, Gênero e Trabalho nas Escolas Públicas"}

Através de um curso, com duração de três a cinco dias ${ }^{12}$, procuramos criar as condições para uma fértil confrontação entre o conhecimento científico e a experiência gerada nas situações de trabalho, além de dar início à construção da 'comunidade ampliada de pesquisa'. Desenvolvemos, então, um curso cuja sistemática não eliminasse a ênfase contida na própria palavra - seu caráter de movimento, fluxos - , onde o debate e a crítica fossem favorecidos. Os procedimentos adotados nessa etapa foram:

a) Apresentação sucinta da proposta metodológica do Programa de Formação13 e de alguns dos conceitos e resultados de pesquisas 14 , seguida da leitura de textos sobre os mesmos temas, contidos em um Caderno de Textos, envolvendo os seguintes tópicos: As comunidades ampliadas de pesquisa; Saúde, cadê você? Cadê você?; As relações de gênero e o mundo do trabalho; Trabalho na escola; Formas de gestão da escola e suas relações com a saúde de quem nela trabalha; Quando o trabalho na escola representa um risco para a 
saúde; Questionando a readaptação profissional. Dessa forma, "devolvemos" os resultados de diversas pesquisas já efetuadas, pretendendo preparar os trabalhadores - após nossa exposição e a leitura dos textos — , tanto para a discussão e a crítica desses materiais, como para a emergência e desenvolvimento de sua própria experiência, em condições de melhor avaliar os limites dos saberes produzidos, assim como sua importância.

b) Discussão temática em "subgrupos": a partir do que foi apresentado e lido, a discussão pode se transformar no momento privilegiado de resgate produtivo da experiência situada dos trabalhadores, no momento de identificação dos aspectos singulares e históricos das situações de trabalho e das experiências. Isto é, momento em que os trabalhadores expressam sua compreensão sobre a realidade e o real de seu trabalho, oportunizando o desenvolvimento desta compreensão. Sim, pois não se trata aqui de uma mistificação da experiência vivida. Ao contrário, conforme Vigotski (1997), a dinâmica da vida subjetiva está ligada ao poder do sujeito de separar-se de sua própria experiência, a fim de que ela se transforme em um meio de resultar em outras experiências.

A dinâmica de funcionamento da discussão envolvia um tipo de coordenação que procurava interferir o mínimo possível no fluxo do 'fazer grupo', estimulando a participação de todos, evitando dar qualquer direção ou avaliação não referente à dinâmica grupal. A discussão era acompanhada por pesquisadores-observadores, que registravam o processo da discussão e os tópicos tratados, com gravação em fita cassete. Sem a presença do especialista expositor do tema específico, os trabalhadores ficavam mais à vontade para expressar suas divergências diante das formulações apresentadas e para construir os próprios discursos, a partir do ponto de vista da atividade de trabalho. Este momento de discussão em "subgrupos" revelou-se como a parte mais importante do curso, visto que os trabalhadores conseguiram verbalizar um outro ponto de vista do tema, distinto do que havia sido apresentado pelos pesquisadores, e perceber a importância da própria experiência.

c) Discussão no "grupo integral", após discussão em "subgrupos": Momento em que se conheciam e comparavam as experiências anteriormente resgatadas, explorando a abordagem sobre a temática específica.

d) Identificação das questões mais relevantes que emergiram das discussões, definindo-se possíveis focos geradores de estudo de campo, escolhendo-se alguns para a realização de exercícios de estudo, preferencialmente em duplas. Tendo como base o conjunto das discussões, apresentamos aos participantes as questões que percebemos como as mais relevantes e mobilizadoras. Após um debate, os trabalhadores escolhiam de três a cinco focos de estudo15. Definiam-se, então, as duplas e os locais do exercício de estudo de campo; além disso, os alunos eram estimulados e preparados para as estratégias e os procedimentos específicos de estudo. 
e) Para gerar subsídios à pesquisa, após cada curso a equipe encaminhava a análise dos registros, na forma de relatórios e gravações de fitas transcritas, com as discussões dos grupos e do coletivo dos participantes.

\section{Fase 2: Retorno às escolas e exercícios de estudo de campo}

Conforme a estratégia metodológica de alternância, na fase seguinte voltase para as escolas a fim de exercitar a capacidade de estudo de campo (centrado nos focos escolhidos), para o qual a dupla deveria procurar mobilizar outros colegas nas escolas. Cada exercício, para o qual delimitou-se o período de um mês, seria, sempre que possível e demandado, acompanhado por membros da equipe16. Após a intensa preparação, essa etapa permitiu uma "desnaturalização do olhar" sobre o trabalho na escola. Era importante verificar como esses problemas, em foco, se materializavam em cada escola ou, ao contrário, não se apresentavam. As duplas, a partir da orientação dada durante o curso, definiam as estratégias e procedimentos a adotar, tais como: observações, entrevistas dialógicas, conversas; leitura de documentos pertinentes; tentativas de mudança implementadas sobre a relação saúde-trabalho; diferentes formas de registro; elaboração de relatórios dos exercícios.

\section{Fase 3: Discussão com a 'comunidade ampliada de pesquisa'}

Realizado o exercício, ocorriam mensalmente os encontros da 'comunidade ampliada de pesquisa', quando as duplas apresentavam e discutiam os materiais gerados. Essa alternância - curso, exercício de estudo de campo na escola e discussão na comunidade - permitia a comparação dos resultados encontrados pelos trabalhadores, o enriquecimento das análises e a constituição de uma 'zona de convergência' entre formas de conhecimento (Schwartz, 2000a) em direção a uma validação coletiva.

A hipótese de base desse tipo de experimentação é que todo conhecimento sobre o trabalho demanda sua validação constante pela experiência (do trabalho), no exercício de confrontação sistemática, quando o conceito pode aprender com o que emerge da situação concreta (do trabalho real). A partir do espaço de 'penumbra simbólica' que se estabelece entre os dois eixos (do conceito e da experiência), a partir da relação entre atividade e discurso, entre o fazer e o dizer, pode-se então também ter acesso ao 'real do trabalho' por um processo em que a atividade de linguagem sobre a atividade de trabalho contribui para elucidá-la, constituindo-se numa zona de desenvolvimento da experiência e do conceito. 
Também nesta etapa, cada apresentação era acompanhada por pesquisadores-observadores, com registro dos tópicos tratados e gravação das exposições. Assim como nas etapas anteriores, gerou-se material para análise, sejam as fitas, com gravações desses encontros, transcritas, sejam os relatórios da equipe, sejam os realizados e apresentados pelos participantes do Programa.

O acesso à experiência não é simples, pois sua principal característica é a opacidade, seja para o observador ou para o próprio sujeito, daí este esforço de criar uma atividade (de linguagem) sobre a própria atividade (de trabalho), re-apresentando-se a experiência e colocando-a em análise. As condições para esse tipo de diálogo estão por se desenvolver. Apresentamos aqui apenas considerações a partir de uma das experimentações possíveis nesta direção.

Todo este processo, que terminou nos encontros da 'comunidade ampliada de pesquisa', procurou instituir-se como um recurso para reinscrever de outro modo o vivido em novas possibilidades de agir. Um trabalho no plano da linguagem se destaca, visto que os processos produtivos são extremamente rebeldes à formalização. A questão não está, portanto, na ausência de palavras, em um 'déficit linguageiro' pelos trabalhadores, mas falar do trabalho implica trabalhar a fala, sendo o foco central o acesso ao não-dito.

\section{Evolução e resultados}

As atividades propostas pelo Programa de Formação foram organizadas em parceria com a Secretaria de Saúde do Sindicato Estadual dos Profissionais de Educação do Rio de Janeiro (SEPE-RJ)17, que se responsabilizou em divulgar o Programa entre os trabalhadores e subsidiou parcialmente sua realização18.

Entre os participantes do primeiro ciclo desse Programa, havia 14 sindicalistas indicados pelo SEPE, tendo em vista tanto garantir a perspectiva de gênero, através da presença de um número expressivo de mulheres, como a diversidade quanto ao cargo ocupado na escola e quanto à região em que atuavam, além de incluir as diferentes tendências políticas formalmente presentes no movimento de trabalhadores de escola e representadas na direção do sindicato.

Com base nesses critérios, participaram sete mulheres e sete homens, sendo cinco professoras, quatro professores, um animador cultural, uma merendeira, uma inspetora de alunos, um servente e um agente de biblioteca. No sindicato, se ocupavam de diferentes funções, como direção da Secretaria de Saúde e da Secretaria de Gênero, Anti-Racismo e Orientação Sexual, Coordenação Geral de Regional ou Núcleo, membros da Diretoria Fi- 
nanceira, da Coordenação de Formação, da Secretaria de Funcionários e da Secretaria de Formação e Cultura. Do total, oito tinham licença sindical, sete eram vinculados à rede estadual, três à rede municipal e quatro a ambas.

Quanto às áreas de ação, os participantes eram lideranças de Regionais do município do Rio de Janeiro ou de Núcleos de outros municípios do estado. Do município do Rio, o primeiro grupo contou com trabalhadores de Madureira e Cascadura (Regional II), Leopoldina (Regional IV), Campo Grande (Regional IV) e Bangu (Regional VIII), além de um militante do SEPE Central. Eram provenientes, no estado, dos seguintes núcleos: Duque de Caxias, Angra dos Reis, Barra Mansa e Volta Redonda.

A composição diversificada desse primeiro grupo foi positiva porque permitiu que emergissem múltiplos aspectos das questões tratadas. A abrangência regional possibilitou uma expansão imediata dessa rede de formação e pesquisa. Os sindicalistas que participaram do primeiro ciclo do Programa iniciaram o segundo como "multiplicadores" (na formação de "multiplicadores de base"), acompanhados por membros da equipe técnica, ampliando o raio de ação do Programa e reproduzindo, com adaptações, a experiência do curso e das alternâncias.

Esse momento envolveu cerca de 100 trabalhadores (merendeiras, serventes, professores, entre outros) e cinco cursos: um destinado a trabalhadores do Médio Paraíba e Angra dos Reis, um destinado à Zona Oeste do município do Rio de Janeiro, um dirigido às áreas da Leopoldina e Madureira, outro à Baixada Fluminense e mais um ao Médio Paraíba.

Ao longo desse processo, como foi dito, foram feitos muitos registros, tanto durante os cursos quanto durante os encontros da comunidade ampliada de pesquisa, no momento em que se debatia o que os participantes apresentavam como seus exercícios de estudo de campo. Todo material registrado reflete, então, o resultado dessa confrontação entre os saberes acadêmicos e práticos, pois estes saberes foram produzidos a partir de sucessivas exposições de especialistas e trabalhadores.

Com a análise desses registros, a partir da leitura exaustiva dos relatórios elaborados pela equipe, assim como das transcrições das fitas, identificaram-se as principais problemáticas que condicionam a saúde desses trabalhadores: o espaço; as relações intersubjetivas; a intensificação do trabalho; e a ausência de um sistema adequado ao acompanhamento e à atenção à saúde desses profissionais.

O espaço, para além da precariedade das instalações encontradas nas escolas estudadas, foi avaliado como não propício à integração desses trabalhadores. A isso se soma o que entendemos como problemas ligados às relações intersubjetivas: falta de reconhecimento e valorização do trabalho, relações autoritárias, discriminações de gênero e falta de autonomia. Quanto aos fatores de intensificação do trabalho, destacaram-se as jornadas exten- 
sas, o número excessivo de alunos e as novas exigências criadas pelos recentes projetos governamentais. Em relação à atenção à saúde, as dificuldades são muitas, entre elas o fato de que não se faz avaliação epidemiológica dos problemas de saúde que acometem esse grupo, assim como não há uma vigilância sistemática sobre seus ambientes de trabalho.

Salientamos que muitas questões relacionadas à divisão sexual do trabalho e às relações de gênero têm vindo à tona nesta pesquisa. No Brasil deu-se, a partir do início do século XX, o abandono da profissão de professor deste nível de ensino pelos homens (Neves, 2001, p. 28) e a feminização desta profissão, em paralelo ao crescimento da rede pública de ensino e à precarização do trabalho nas escolas. A relação com trabalho doméstico teve um papel importante para a desvalorização e desqualificação das atividades realizadas e de quem as executa. Esse processo é demonstrado tanto do ponto de vista socioeconômico (baixos salários etc.) quanto do simbólico (pouca visibilidade social e reconhecimento).

Para os trabalhadores, foi possível, com esse dispositivo de pesquisaformação, delimitar um conjunto de questões críticas, questões que revelam problemas de diversas naturezas e que contrariam a conquista da saúde. Se nos apoiarmos no dispositivo de três pólos (Schwartz, 2000a), podemos entender cada uma dessas questões como (re)convocações ao pólo da ciência para a realização de novas pesquisas específicas. Em outras palavras, do ponto de vista epistemológico, através desse método indireto de análise das situações de trabalho, identificamos problemáticas que se colocam para os trabalhadores como centrais e bastante concretas em suas vidas. Algumas dessas questões podem ser assim explicitadas:

a) Como os trabalhadores podem transformar o espaço das escolas em um lugar favorável não apenas ao processo educativo, de ensino-aprendizagem, como também à construção e desenvolvimento de coletivos de trabalho e à promoção da saúde?

b) Que tipo de acolhimento os trabalhadores já atingidos em sua saúde, colocados em situação de "readaptação profissional", deveriam receber para deixarem de ser discriminados nas escolas (quando então se caracteriza mais uma violência)?

c) Considerando a importância da dinâmica do reconhecimento no trabalho para a saúde mental e a 'economia psicossomática', como os trabalhadores podem conquistar um maior reconhecimento (à altura do investimento e da contribuição dada, em geral) por parte da sociedade, das autoridades governamentais em seus diversos níveis, das famílias e dos alunos (de quem ainda registram alguma valorização) por seu envolvimento na realização das atividades diárias?

d) Como enfrentar o problema da "contaminação/invasão" da vida familiar pelo trabalho na escola? 
e) Como enfrentar os problemas relativos aos deslocamentos entre a casa e as diversas escolas em que se trabalha?

f) Como enfrentar os problemas ambientais que interferem no processo de trabalho das escolas, como ruído e poluição?

Ao aprofundar a discussão sobre essas questões, os trabalhadores começam a esboçar alternativas de transformação, para além da luta salarial, deste quadro negativo. Ou seja, buscam caminhos para práticas de prevenção e promoção da saúde a partir do local de trabalho (Silva, 2003), que envolvem ações diversificadas no âmbito da vigilância à saúde, da assistência e da intervenção nos processos de trabalho (mudanças dos instrumentos, do espaço, das formas de gestão etc.).

Os trabalhadores de escola que participaram do Programa modificaram seu olhar sobre a instituição (o que foi verbalizado em seus relatos e verificado em nossa avaliação), entrando em sinergia com a apropriação dos conceitos operados pela equipe de especialistas. Neste trânsito entre a situação cotidiana e a de formação (no exercício de estudo de campo), uma nova compreensão emerge, pois, conforme Bakthin (1984), compreender significa pensar em um contexto novo, sendo que, nesse deslocamento do vivido, ele se separa da atividade, torna-se disponível para a consciência e se enriquece das propriedades do novo contexto.

Para Vigostki (1978), só no movimento um corpo mostra o que ele é, daí o acesso ao real da atividade demanda a criação de um meio de trabalho "extra-ordinário", que mobilize para uma ação reflexiva sobre a atividade "ordinária" de cada um, uma atividade sobre a atividade, em condições de deslocar esta última.

Nesse percurso de desenvolvimento da própria experiência, os participantes começaram a assumir o papel de expositores nos cursos e mesmo a autoria de textos sobre o tema. Observa-se também uma presença maior da temática saúde, trabalho e gênero em eventos sindicais e no embate com representantes dos governos. Essa abordagem teórico-metodológica tem possibilitado a identificação de uma dinâmica mais complexa nas relações entre o ambiente de trabalho e as formas de mal-estar e adoecimento entre esses profissionais, superando a lógica "causa-efeito".

Destacamos também que, como um desdobramento desse Programa, iniciou-se o desenvolvimento de instrumentos para o monitoramento permanente das relações entre saúde, gênero e trabalho, a ser realizado pelos próprios trabalhadores. Uma experiência-piloto usando esses instrumentos está sendo implementada em uma escola de Barra Mansa. Nessa mesma escola, participantes do Programa criaram um site experimental, na perspectiva de um observatório das relações entre saúde, gênero e trabalho, ou seja, um sistema de divulgação de informações e análises sobre essas relações. 


\section{Considerações finais}

Debatemos, aqui, algumas considerações epistemológicas, conceituais e metodológicas no campo de investigação em saúde e trabalho, em interface com a educação (seja em relação ao trabalho na escola, seja em relação à formação de adultos). Apresentamos reflexões a partir de uma experimentação que procurou conjugar formação-pesquisa-intervenção, sinalizando para a necessidade de um debate sobre a definição dos objetivos das pesquisas desenvolvidas nesse campo, assim como sobre a necessidade de construção de métodos adequados à premissa de que aqueles/as que vivem a experiência do trabalho são detentores de um tipo de saber imprescindível para a produção de conhecimento científico relativo a essa temática.

Essa experimentação permite também uma reflexão sobre as possibilidades de articularmos pesquisa à formação (educação) dos trabalhadores e, simultaneamente, à criação de meios para a promoção e produção da saúde, segundo uma abordagem sintetizada no 'compreender-transformar'. Em outras palavras, implica pensar sobre a relação pesquisa e intervenção, que não necessariamente devem ocorrer em tempos diferentes.

Primeiramente, parece-nos que a definição dos objetivos de uma pesquisa em saúde e trabalho exige inverter o sentido da abordagem: deve partir do campo, ou seja, deve privilegiar o ponto de vista da atividade. Tratase de uma questão ética e epistemológica. Ética porque exige que o pesquisador se confronte com algumas perguntas, como: o que o trabalhador quer e/ou precisa saber? quais sãos suas preocupações? Epistemológica porque remete ao valor do conhecimento produzido e a suas potencialidades.

Quanto ao pólo da experiência, lembramos que os primeiros participantes da formação faziam parte da direção sindical, em algum nível. A herança da lógica sindical entre nós está baseada na detenção da verdade acerca do 'que fazer', operando junto aos colegas através de palavras de ordem. Junto às "bases", cabe conscientizá-las, levar a 'boa nova', uma fala pré-escrita/prescrita. Neste contexto, a participação no Programa de Formação, que envolve ir a campo (voltar às escolas) junto aos colegas para descobrir algo, para produzir conhecimento, e não levar um produto cristalizado, cria muitas vezes uma desestabilização da lógica de cima para baixo/descendente.

Diante do perigo da emergência do sofrimento (ou mesmo sua presença), a mobilização psicológica é muito mais forte em direção à construção de sistemas defensivos do que para a produção de conhecimento. Outro fator, ligado aos sindicalistas, é uma agenda permanentemente lotada. É praticamente impossível um planejamento de médio prazo (ou mesmo de curto prazo), pois as prioridades são freqüentemente recolocadas pela conjuntura mutante, no contexto de precarização e degradação em que vivemos. 
Com relação aos trabalhadores "de base", um conjunto de obstáculos também se coloca. Jornadas massacrantes, ausência de experiências de luta com vitórias sequer parciais, presença de "ideologias defensivas" (Dejours, 1993) em relação à saúde, tudo isso coloca uma série de dificuldades importantes ao Programa de Formação.

Não obstante, tanto em um caso como no outro, trata-se de dificuldades já esperadas, isto já é velho. O novo que conseguiu nascer foi exatamente a possibilidade de colocar estes velhos obstáculos em análise, aí está uma das riquezas do dispositivo de formação gerado. O que nos surpreendeu, desde a formulação da demanda, foi que frente ao incômodo pelo déficit provocado pela redução do número de colegas em plenas condições de trabalho (e o mais trabalho como efeito) o encaminhamento solicitado era diferente: compreender para transformar este quadro perverso.

Quanto ao terceiro pólo, ético-epistêmico, que faz a gestão entre os outros dois, duras dificuldades vêm se impondo. A tradição exclusivamente salarial da luta sindical reflete-se na enorme dificuldade para compreender que salário e saúde estão articulados como instrumentos de garantia e afirmação da vida. Quando a questão da saúde entra no debate, o faz como ausência, e se articula com salário, sim, de forma perversa. A saúde, neste caso, talvez pudesse ser vendida, como o fazem outras categorias de trabalhadores (adicionais de insalubridade etc.).

Outra forma de emergência da "questão saúde" tem sido através de uma oposição polarizada entre luta pelo Sistema Único de Saúde e equipamento hospitalar público (IASERJ) e pela adesão a algum plano de saúde privado. Este debate se apresenta na forma de opções mutuamente excludentes, mantendo oculta a discussão da cotidiana luta que se faz necessária pela vigilância e promoção de saúde daqueles/as que trabalham nas escolas.

Quanto ao pólo dos conceitos, as dificuldades não são menores. Nossa herança escravocrata e de soberba em relação aos trabalhadores não favorece a perspectiva de humildade epistemológica, de reconhecimento prático de que o conhecimento do trabalho e da saúde (das relações entre saúde-trabalho) exige a interrogação dos saberes investidos no trabalho. Exige admitir que o conceito científico não pode conter inteiramente uma realidade sempre singular, bem como aceitar que existe uma "dupla antecipação", de tal modo que a experiência está sempre em avanço em relação ao conceito (e vice-versa). Tal compreensão não é suficiente, muitas vezes, para eliminar um obstáculo epistemológico que se aprende e "imprende" ao longo da formação como universitário: a pretensão e a arrogância, esta forma de ignorância impermeável.

Com relação ao campo da Saúde dos Trabalhadores, em nossa avaliação perdura uma grande defasagem entre formulação teórica e proposta metodológica. O diálogo com os trabalhadores propicia colocar em xeque nosso 
patrimônio conceitual, exige o exercício de uma humildade epistemológica, nos mobilizando para novas investigações, sempre articuladas à criação de alternativas e proposições práticas. O caso dos trabalhadores de escolas públicas é um exemplo concreto dessa afirmação. Esses trabalhadores apontam questões muito pouco conhecidas e analisadas, assim como alertam para a ausência de um sistema de acompanhamento mais sistemático sobre suas condições de trabalho e os sinais de adoecimento desse grupo populacional.

A relação dialógica com eles sinaliza conflitos e dificuldades que estão presentes em suas atividades de produção de serviço e que têm implicado em um inaceitável custo para sua saúde, que só podem ser melhor compreendidos com uma abordagem situada e que privilegie suas experiências cotidianas. Sendo assim, nosso maior desafio é a construção de métodos que permitam incorporar essas experiências e mesmo desenvolvê-las, isto é, torná-las mais fortes/potentes, tendo em vista uma ampliação da capacidade de defesa da saúde.

O diálogo, a confrontação de pontos de vista e a circulação de informações e idéias são fundamentais para que essa atividade sempre enigmática - o trabalho - seja mais bem compreendida e não se constitua numa oposição à conquista da saúde. Por outro lado, a formação dos trabalhadores em relação à saúde e ao trabalho apresenta-se como um elemento importante, tanto para a realização de suas atividades de trabalho (conforme as exigências de produtividade e qualidade), quanto para a geração de conhecimentos sobre essas relações e para a promoção da saúde desses grupos. Todas essas questões sinalizam a importância de apreendermos, de forma articulada, o trinômio trabalho-saúde-educação.

\section{Notas}

l Jussara Brito, Doutora em Saúde Pública pela Fundação Oswaldo Cruz, com pósdoutorado em Ergologia - Análise Pluridisciplinar de Situações de Trabalho pela Université de Provence/França. Pesquisadora do Centro de Estudos da Saúde do Trabalhador e Ecologia Humana, Escola Nacional de Saúde Pública <jussara@ensp.fiocruz.br>

2 Milton Athayde, Doutor em Engenharia de Produção (Gerência da Produção/Ergonomia) pela Coppe/UFRJ, com pós-doutorado em Ergologia — Análise Pluridisciplinar de Situações de Trabalho pela Université de Provence/França. Docente do Instituto de Psicologia/ Programa de Pós-Graduação em Psicologia Social, Universidade do Estado do Rio de Janeiro<miltonathayde@uol.com.br> 
3 A idéia de exterritorialité opera com esta palavra que, na língua francesa, significa a imunidade que isenta os agentes diplomáticos da jurisdição do Estado em que eles se encontram.

4 Seu entendimento enquanto modos operatórios observáveis.

5 Utilizamos esta expressão entre aspas porque se trata de uma denominação utilizada pela administração para encaminhar a situação de trabalhadoras que procuram ajuda médica e são consideradas pela perícia como sem condições de realização normal das atividades, podendo entretanto realizar parte das tarefas. Um quadro complexo, a ser melhor compreendido (Nunes, 2000), sendo as aspas reveladoras de nosso objetivo de colocá-la em análise e transformá-la.

6 Mal estar entendido por Esteve como efeitos permanentes de caráter negativo que afetam a personalidade do professor, como resultado das condições em que exercem a docência. Manifestam-se, inicialmente, por formas de absenteísmo e desembocam no abandono da profissão. A inibição e o denominado "recurso à rotina" são as modalidades a que se apela para cortar as implicações pessoais com a docência e eliminar as tensões que dela se derivam.

7 Fruto da parceria da Universidade de Brasília com a Confederação Nacional dos Trabalhadores de Educação.

8 Parceria da Universidade Federal da Bahia com o Sindicato dos Professores do Estado da Bahia e a Confederação Nacional dos Trabalhadores em Estabelecimentos de Ensino.

9 Mesmo para os próprios sujeitos da experiência apresenta-se uma dificuldade, como veremos.

10 A seleção dos participantes é sempre feita em parceria com o sindicato e a composição do primeiro grupo no Rio de Janeiro ("multiplicadores") será apresentado posteriormente.

11 No primeiro ciclo, quatro exercícios de estudo de campo, a cada mês; nos seguintes, três exercícios.

$12 \mathrm{O}$ primeiro teve a duração de cinco dias, hospedados em um centro de treinamento afastado de seus locais de trabalho e moradia. Os demais passaram a ter a duração de três dias, nas suas próprias regiões. As razões para as diferenças são estritamente de limitações operacionais, pois preferiríamos que tivesse o mesmo tipo de estrutura do primeiro.

13 A proposição envolve, portanto, o necessário acordo do grupo de participantes, o que se mostra como algo a ser sempre negociado, de um modo ou de outro.

14 Selecionamos aqueles que consideramos os mais importantes e geradores de discussão. Neste momento da apresentação, na presença do especialista, a palavra está aberta para esclarecimentos, não à discussão, o que deve ocorrer em outro momento.

15 Nos ciclos posteriores, o número de focos passou a ser sempre três.

16 Lamentavelmente, na experimentação efetuada no Rio de Janeiro, dado o tamanho da rede de ensino e nossa pequena equipe, esta exigência poucas vezes foi viabilizada. 
17 A solicitação foi apresentada na Escola Nacional de Saúde Pública (ENSP/Fiocruz), sendo assumida por um de seus grupos de pesquisa (Saúde e Relações de Trabalho e Gênero). Posteriormente, houve a ampliação deste grupo, tornando-se mais interdisciplinar e multiprofissional, além de interinstitucional, incorporando um profissional e estudantes de iniciação científica da UERJ, contando com a colaboração de profissionais e estudantes da UFPB (que a partir da constituição do Programa de Formação passaram a fazer parte desta equipe central e a desenvolverem este Programa em João Pessoa-PB) e da UFES (que vêm colaborando sistematicamente ao longo do processo e desenvolvendo de forma diferenciada esta mesma lógica de pesquisa-intervenção em Vitória-ES).

18 Como foi sinalizado na nota anterior, constituiu-se uma equipe interinstitucional, sendo realizado um acordo internacional envolvendo o Fundo para Igualdade de Gênero/ Agência Canadense para o Desenvolvimento Internacional, que apoiou este projeto, e a Associação Brasileira de Pós-graduação em Saúde Coletiva (ABRASCO). Além disso, embora tenhamos acompanhado a evolução desse Programa na cidade de João Pessoa, nossas reflexões, neste artigo, estão baseadas na experimentação realizada no estado do Rio de Janeiro, que contou, além dos dois autores, com uma equipe composta pelas pesquisadoras Kátia Reis de Souza e Blandina Marques dos Santos (CESTEH/ENSP) e pelo então doutorando Edil Ferreira da Silva (cuja tese analisa as potencialidades desse Programa para a promoção da saúde), além de outros pós-graduandos e estagiários de iniciação científica (ENSP e UERJ). A equipe de João Pessoa foi coordenada por dois docentes da UFPB, Mary Yale Neves e Hélder Pordeus Muniz.

\section{Referências}

BAKHTIN, Michäil. 1984. Esthétique de la création verbale. Paris: Gallimard.

BARROS, Bete. 1997. A transformação do cotidiano: vias de formação do educador: a experiência da administração de Vitória. Vitória: EDUFES.

BENEVIDES BARROS, Regina. 1994. Grupo: afirmação de um simulacro. Tese de Doutorado. São Paulo: Pontifícia Universidade Católica de São Paulo.

BETANCOURT, Oscar e Palacios, Miguel. 1999. Trabajo y salud en el magisterio del Ecuador. Salud de los trabajadores. 7(2):101-121

BRITO, Jussara; ATHAYDE, Milton; BARROS, Maria Elisabeth; NEVES, Mary Yale (orgs.). 2001. Trabalhar na Escola? Só inventando o prazer. Rio de Janeiro: Edições IPUB/UFRJ-CUCA.

; ATHAYDE, Milton; NEVES, Mary Yale (orgs.). 1998. Saúde e trabalho nas escolas. Rio de Janeiro: CESTEH/ENSP/FIOCRUZ.

BRITO, Jussara et al. 1998. O trabalho das merendeiras e serventes das escolas públicas do Rio de Janeiro: um debate sobre saúde e gênero. In: Saúde e Trabalho na Escola (Brito, J., Athayde, M.; Neves, M., orgs.), pp. 7-21, Rio de Janeiro: CESTEH/ENSP.

CANGUILHEM, George. [1947] 2001. Meios e normas do homem no trabalho. Proposições, 12(2-3):109-121.

1992. La connaissance de la vie. Edição revista e ampliada. Paris: Vrin. 1990. O Normal e o patológico. 3a ed. revisada e aumentada. Rio de Janeiro: Forense Universitária.

CARPENTIER-ROY, Marie-Claire. 1992. Organisation du travail et santé mentale 
chez les enseignantes et les enseignants du primaire et du seconde. Canadá: Rapport de Recherche.

CHABAUD-RYCHTER, Danielle; FOUGEYROLLAS-SCHWEBEL, Dominique; SONTHONNAX, Françoise. 1985. Espace et temps du travail domestique. Paris: Librairie des Méridiens.

CLOT, Yves. 1997. Le projet au risque de l'activité. Pratiques psychologiques, 1(1): 53-62.

—. 1999. La fonction psychologique du travail. Paris: PUF.

—. 2001. FAÏTA, Daniel; FERNANDEZ, Gabriel; SCHELLER, Livia. Entretiens en autoconfrontation croisé: une méthode en clinique de l'activité. Education Permanente, 146:17-27.

CODO, Wanderley et al. 1999. Educação: carinho e trabalho. Petrópolis: Vozes/Brasília: CNTE-UNB.

DEJOURS, Christophe. [1980] 1993. Travail, usure mentale: de la psychopathologie du travail à la psychodynamique du travail. Paris: Bayard.

DIAS, Elisabeth. 1994. A atenção à saúde dos Trabalhadores no Setor Saúde (SUS) no Brasil: realidade, fantasia, utopia? Tese de Doutorado. Campinas: FCM/ Unicamp.

DUC, Marcelle. 2002. Le travail en chantier. Toulouse: Octarès.

ESTEVE, José Manoel. 1994. O mal-estar docente: a sala de aula e a saúde dos professores. Bauru: Edusc.

FAÏTA, Daniel e SCHWARTZ, Yves. 1985. Pour mieux connaître les forces productives: object et genèse d'une expérience. In: L'Homme producteur: autour des mutations du travail et des savoirs (Schwartz, Y. e Faïta, D., resps.). pp. 925. Paris: Messidor/Eds. Sociales.

GOMES, Luciana. 2002. Trabalho multifacetado de professores/as: a saúde entre limites. Dissertação de Mestrado. Rio de Janeiro: ENSP/Fiocruz.

HIRATA, Helena. 2000. Globalização, trabalho e gênero. In: o valor simbólico do trabalho e o sujeito contemporâneo (Jerusalinsky, A. et al.). Porto Alegre: Artes e Ofícios.

KERGOAT, Danièlle. 1996. Relações Sociais de sexo e divisão sexual do trabalho. In: Gênero e Saúde (Lopes, Marta Júlia; Meyer, Dagmar; Waldow, Vera, orgs.). Porto Alegre: Artes Médicas.

LEPLAT, Jacques; HOC, Jean-Marie. 1983. Tâche et activité dans l'analyse psychologique des situations. Cahiers de Psychologie Cognitive, 3(1):49-63.

MARTÍNEZ, Deolinda; VALLES, Iris; KOHEN, Jorge. 1997. Salud y trabajo docente: tramas del malestar en la escuela. Buenos Aires: Kapelusz.

MARX, Karl. 1948. Le Capital, Livre I tome 1. Paris: Editions Sociales.

MONTMOLLIN, Maurice. 1997. Vocabulaire de l'Ergonomie. Toulouse: Octarès.

NEVES, Magda. 1999. Reestruturação Produtiva e Relações de Gênero. Revista do II Congresso Internacional Mulher, Trabalho, Saúde, pp. 17-22.

NEVES, Mary Yale; SELIGMANN-SILVA, Edith. 2001. Trabalho docente: precarização e feminização de uma prática profissional. In: Trabalhar na escola? 'Só inventando o prazer' (Brito, Jussara et al., orgs.), pp. 23-50, Rio de Janeiro: IPUB/ CUCA/UFRJ.

NUNES, Bernadete, 2000. O sentido do trabalho para merendeiras e serventes em situação de readaptação nas escolas públias do Rio de Janeiro. 2000. Dissertação de Mestrado (Saúde Pública). Rio de Janeiro: ENSP/FIOCRUZ.

ODDONE, Ivar et al. 1986. Ambiente de trabalho: a luta dos trabalhadores pela saúde. São Paulo: Hucitec.

_ ; RE, Alessandra; BRIANTE, Gianni. 1981. Redécouvrir l'expérience ouvrière. Paris: Éditions Sociales.

SCHWARTZ, Yves. 1988. Expérience et connaissance du travail. Paris: Messidor/ Eds. Sociales.

1992. Travail et usage de soi. In Travail et Philosofie: concocations mutuelles. Toulouse: Octarès. 2000a. Le paradigme ergologique ou un métier de Philosophe. Toulouse: Octarès. 2000b. A Comunidade Científica Ampliada e o Regime de Produção de Saberes. Trabalho e Educação. Revista do NETE, 7:38-46.

SCAVONE, Lucia. 1999. A Produção do Co- 
nhecimento em Trabalho e Saúde: um Olhar de Gênero. Revista do II Congresso Internacional Mulher, Trabalho, Saúde, pp. 9-12.

SILVA, Edil. 2003. Trabalhadores/as de Escola e Construção de uma "Comunidade Ampliada de Pesquisa": Promoção da Saúde a partir dos locais de trabalho. Tese de Doutorado. Rio de Janeiro: ENSP/ FIOCRUZ.

SOUZA, Katia. 2000. Saúde do Trabalhador e Práxis Educativa. Dissertação de Mestrado. Rio de Janeiro: NUTES/UFRJ.

VIGOTSKI, Lev. 1978. Mind in society. Cambridge/Londres: Harvard University Press.
1994. Le problème de la conscience dans la psychologie du comportement. Societé Française, 50:35-47.

1997. Pensée et langage. Paris: Eds. Sociales.

VINCENTI, Antonella. 1999. Ivar Oddone, intelectuell organique et chercheur heterodoxe. Les Territoires do Travail, 3:3342.

VOGEL, Laurent. 2000. Um contributo do Quebeque para um debate indispensável ao movimento sindical na Europa. In: Compreender o trabalho das mulheres para o transformar (Messing, Karen, org.), pp. 9-33, Lisboa: DEPP.CIDES. 